\title{
Der katholische Publizist
}

\author{
von Emil Dovifat
}

\begin{abstract}
Dem Gedenken an N. U. A. De Volder ofm ( $\dagger$ 30. November 1967) und seinen Kampf für eine freie, verantwortungsbewußte Publizistik.
\end{abstract}

Der Publizist, der sich katholisch bekennt, übernimmt damit in Freiheit Verpflichtung und Auftrag. Einen Auftrag aus seinem Glauben, eine Verpflichtung des Gewissens in Dienst und Demut, aus eigenem Entschluß, nicht aus kirchlicher Macht oder konfessioneller Geltung.

So ungefähr wäre, auch nach der Erklärung des III. Weltkongresses für das Laienapostolat ${ }^{1}$, der Auftrag des katholischen Publizisten bestimmt. Er fordert von seiner Kirche das Vertrauen, in einem „uneingeschränkten Freiheitsraum“, dem Raum zu wirken, der ihm durch die katholische Grundhaltung gesichert ist. Also hat er nicht nur das Recht der Gläubigen auf Information zu gewährleisten ${ }^{2}$. Das ist wichtig, aber nicht das Wichtigste. Das Wichtigste steht in der Pastoralkonstitution über "Die Kirche in der Welt von heute" ${ }^{\text {. }}$. Sie fordert die Offnung dieser Kirche in die ganze, auch in die gegnerische Welt: in allen Höhen und Tiefen, über dogmatische, theologische und andere Hemmungen hinweg den Menschen zu suchen, ihm in Zuversicht die frohe Botschaft zu bringen, ihm zu dienen „in jeder Lage, in jeder Schwäche, in jeder Not" ${ }^{*}$.

Der katholische Publizist hat also nicht nur in der egozentrischen Freude, in der jeder Publizist zunächst einmal sich selber ausdrückt, die Feder geistvoll und zwingend zu führen oder mit der gesteigerten Lautungskraft des Mikrophons dem Worte Eindringlichkeit zu geben oder mit dem Tiefblick der Kamera den Dingen und Menschen letzte Erkenntnisse zuzumuten. Alle grandiosen technischen Mittel sind für den katholischen Publizisten niemals Selbstzweck. Sie sind Gottesgeschenke, dazu gegeben, das Wort auch in der Langeweile des Alltags zu Tat und Leistung zu führen. Der katholische Publizist hat alle Kräfte des Geistes und der Überzeugung zur positiven Wirkung einzusetzen. Anarchie und Nihilismus in noch so ästhetischer, noch so polemischer Form dargeboten, bekämpft er vom Kern der Dinge her. Er weiß, daß „der bloße Intellekt kalt und schamlos ist..., der vom Körper her der Demut und vom Herzen her der Liebe bedarf"5.

Von hierher und nicht aus der noch so blendenden Brillanz des Wortes, der Zugkraft der Bosheit, der sexuellen Libertinage, dem demagogischen Machtstreben oder dem kommerziellen Profit baut der katholische Publizist seinen Lebenszweck. Kein Wunder, daß er im lauten Lärm publizistischen Gewoges oft zurückbleibt, kein Wunder aber auch, daß er in den Stunden politischen Zusammenbruches so wie der Staatsmann gleicher Haltung als einer der ersten Verantwortung übernimmt und sich, - man blicke auf 1918 oder 1945, - die Lasten aufbürdet.

Prof. Dr. Emil Dovifat, em. Prof. der Publizistik an der Freien Universität Berlin, langjähriger Direktor des dortigen Instituts für Publizistik. 
Mit den Publizisten anderer Grundhaltung steht der katholische Publizist in gleicher Front zur Verteidigung der Freibeit, weil sie die Lebensgrundlage des pluralistischen Staates ist. Im publizistischen Wettbewerb aber steht er mit ihnen oder doch mit vielen von ihnen keineswegs in Wettbewerbsgleichheit. Er kann die heute so häufige nachrichtenpolitische Bedenkenlosigkeit, alles und jedes in die Offentlichkeit zu zwingen, nicht mitmachen. „Publish and be damned" hemmungslosen Auflagenhochtriebs, kann er nicht teilen. Das Prinzip nimmt sich beinahe aus wie eine Parallele zum wirtschaftlichen Grundsatz des ,Laissez faire, laissez passer, le monde va de lui même': als pendelten aufeinander gehäufte Außerordentlichkeiten sich schließlich von selber in Ordnung. Auch Emile Zolas kühne Doktrin kann er nicht übernehmen: in einer völlig hemmungslos geübten Publizistik werde die Macht der Wahrheit sich bewähren, der „Schmutzstrom selbst werde alles befruchten "7. Wir haben in Deutschland und nicht nur dort erfahren, wie falsch diese Annahme ist, und könnten es wieder erfahren, wenn, nicht wie damals der Schmutzstrom politischer Lüge und Verleumdung, sondern heute die Produktion einer billigen Amüsierindustrie im satten Wohlfahrtsdenken die Massen erfaßt.

"Die Würde des Menschen ist unantastbar". Dieser erste Satz aus Artikel 1 des Grundgesetzes der Bundesrepublik Deutschland ist von gleicher Bedeutung wie der große Satz des Artikels 5: "Jeder hat das Recht, seine Meinung in Wort, Schrift und Bild frei zu äußern und zu verbreiten ... " Beide Sätze miteinander im Zusammenhang zu halten, ist eine Gewissenspflicht und stellt alle Ausbrüche persönlicher Diffamierung, des Rufmordes, der kommerziellen Ausbeute krasser Sensationsfälle oder schwerer persönlicher Schicksale heftig in Frage.

Der katholische Publizist begrüßt Gesetzesbestimmungen, wie sie jüngst in Deutschland in den Pressegesetzen der Länder festgelegt wurden, daß nämlich alle publizistische Arbeit öffentliche Aufgaben ${ }^{8}$ freiwillig und aus eigener Verantwotung zu erfüllen hat und ihr somit ein Wächteramt im öffentlichen Leben gegeben ist. Es ist sehr ernst und sehr entschieden wahrzunehmen. Es gehört in den ganz natürlichen Mechanismus nicht nur demokratischer, sondern auch menschlicher Kontrolle. Ihre Freiheit sollte bis zum letzten verteidigt, aber auch aus strenger Sachkunde geübt werden, - in geistiger Qualifikation ${ }^{\theta}$. Sie wiederum erfordert praktische Erfahrung, persönliche Mitarbeit, um aus eigenem Miterleben die rechten Maßstäbe zu finden und so die Grenzen des Kritischen abzustecken, - zu wissen aber auch, wo im öffentlichen Leben die großen Erfolge, die bleibenden Fortschritte erzielt worden und damit auch anzuerkennen sind.

Nichts lähmt mehr als das eisige Grau nörgelnder Überwachung. Die freie Demokratie bedarf da, wo sie Erfolge bringt und Erfolge erreichen soll, auch der Sonnenwärme der Freude, zumal da, wo die freie Mitwirkung aller dazu beitrug, ein Ziel zu erreichen. Der größte Publizist des hohen Mittelalters, Bernhard von Clairvaux, hat dies gemeint, wenn er in eine sich verzehrende Zeit hineinrief: „Mögen andere schelten, ich will bewundern!" Dies steckt auch in den Anfangsworten der Pastoralkonstitution: Gaudium et spes. Es ist ein publizistisches Programm.

Ein Programm, das immer wieder auf den Menschen gerichtet ist, den in der vielgepriesenen Autonomie seines Ichs oft so hilf- und hoffnungslos, so grauenvoll isolierten Menschen, der in der Masse und ihrem Treiben versinkt oder zur Seite gespült wird. Ihn anzusprechen und immer wieder zu finden, ist die katholische Verpflichtung in der Publizistik, in den "communicationes sociales" des Konzils.

Es erhebt sich dann auch die religiöse Lösung des Problems der Masse. Guardini kündet es in seiner mächtigen Sprache: „Nur Gott ist einmalig." Vor ihm steht 
auch die menschliche Person in der Zahl, „hier legt sie ihre Kronen nieder“. Sich vor Gott in die Zahl stellen und für sie und mit ihm dienen, - „das ist die letzte Wahrheit und Freiheit".

\section{Anmerkungen:}

1. Bericht „Kirche und Publizistik“ über den Arbeitskreis „Soziale Kommunikation “ des III. Weltkongresses für das Laienapostolat in Rom (Oktober 1967) in: „KNA-Informationsdienst “, Bonn, 15. Jg. 1967, Nr. 42 (19. Okt.), S. 4. Vgl. ferner den kurzen Bericht in dieser Zeitschrift. S. $46 \mathrm{f}$. sowie die Zusammenfassung im Informationsdienst „ido-c ${ }^{\alpha}$, Rom, Doss. 67-37 (22. 10. 1967).

2. Punkt 3 der Entschließung des o. a. Arbeitskreises.

3. Deutsche Fassung der Konstitution in Karl Rahner und Herbert Vorgrimler (Hrsg.): Kleines Konzilskompendium, Freiburg 1966, S. 449-552.

4. Ansprache Papst Pauls VI. während der öffentlichen Sitzung des Zweiten Vatikanischen Konzils am 7. Dezember 1965, hier nach dem Abdruck in Xavier Rynne: Die Erneuerung der Kirche, Köln-Berlin 1967, S. 370.

5. Romano Guardini: Spiegel und Gleichnis, Mainz 1948, S. 41.

6. Hugh Cudlipp: Publish and Be Damned, London 1955. Der Buchtitel nimmt sich fast wie eine Ideologie eines skrupellosen Massenjournalismus aus. Verfasser ist der langjährige Direktor des „Daily Mirror“ (London), der z. Z. auflagestärksten Zeitung im freien Teil Europas.

7. Brief (18. Dez. 1897) Zolas an H. Bérenger. E. Zola, Oeuvres complètes, Paris 1927/29, Bd. 49, S. 792.

8. Berliner Pressegesetz vom 15. Juni 1965, $\$ 3$, Abs. 1. Vgl. auch die anderen Pressegesetze der Bundesländer (meist $\$ 3$ ). Beck'sche Textausgabe "Presserecht", München und Berlin ${ }^{3} 1966$.

9. „publizistische Bildungsarbeit": Punkt 2 der Ergebnisse des oben (Anm. 1.) erwähnten Arbeitskreises "Soziale Kommunikation“.

\section{S U M M A R Y}

The catholic journalist is obliged to do his work in faith and responsibility. He prefers to write or speak in freedom and he does not like to be controlled by the authority of the official Church. He will always fight anarchy and nihilism. With journalists of all other denominations he joins in defending freedom, the foundation of a democratic society. But the exploitation of freedom of the press and freedom of information should be balanced by the obligation to hold dignity of man in high esteem. Carping criticism must not be the main business of catholic journalism. According to the leading words of one of the Vatican Council's constitutions, "gaudium et spes“, the catholic journalist shall bring the sunny warmth of joy and applause into the field of social communications.

\section{RESUMEN}

El publicista católico, según el Conc. Vaticano II, es una persona atada libremente a su cenciencia y a su fé. Los grandiosos medios modernos de información no son instrumentos para la propia exaltación, sino de transformación de la palabra y el espíritu en realidades concretas al servicio de los hombres.

El periodista católico es un paladín de la libertad cristiana frente a la anarquía, nihilismo, naturalismo, libertinaje o cornercial, demagogía, etc. Conjuga la dignidad del hombre con su derecho inalienable de libertad de expresión. Vigila el diario acontecer „admirando, no echando pestes ${ }^{*}$, tratando de sacar al hombre de la tierra movediza del egoismo para llevarlo a Dios. 